\title{
Specific fatty acid intake and the risk of pancreatic cancer in
}

\section{Canada}

\author{
A Nkondjock ${ }^{1,2}$, D Krewski ${ }^{2}$, KC Johnson ${ }^{3}$, P Ghadirian ${ }^{*, 1,2}$ and the Canadian Cancer Registries Epidemiology \\ Research Group ${ }^{4}$
}

'Epidemiology Research Unit, Research Centre, Centre hospitalier de l'Université de Montréal (CHUM)-Hôtel-Dieu, Montreal, QC, Canada; ${ }^{2}$ McLaughlin Centre for Population Health Risk Assessment, Institute of Population Health, University of Ottawa, Ottawa, ON, Canada; ${ }^{3}$ Surveillance and Risk Assessment Division, Centre for Chronic Disease Prevention and Control, Population and Public Health Branch, Health Canada, Ottawa, Canada

\begin{abstract}
The possible association of specific fatty acid (FA) intake and pancreatic cancer risk was investigated in a population-based casecontrol study of 462 histologically confirmed cases and 472 I frequency-matched controls in eight Canadian provinces between 1994 and 1997. Dietary intake was assessed by means of a self-administered food frequency questionnaire. Unconditional logistic regression was used to assess associations between dietary FAs and pancreatic cancer risk. After adjustment for age, province, body mass index, smoking, educational attainment, fat and total energy intake, statistically significant inverse associations were observed between pancreatic cancer risk and palmitate (odds ratios $(\mathrm{ORs})=0.73 ; 95 \%$ confidence intervals $(\mathrm{Cls})$ 0.56-0.96; $P$-trend $=0.02$ ),

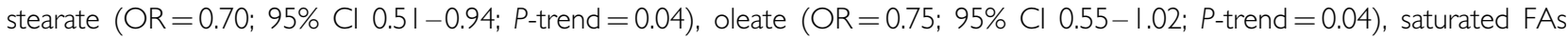
$(\mathrm{OR}=0.67 ; 95 \% \mathrm{Cl} 0.50-0.9 \mathrm{I} ;$ P-trend $=0.0 \mathrm{I})$, and monounsaturated FAs $(\mathrm{OR}=0.72 ; 95 \% \mathrm{Cl} 0.53-0.98 ; P$-trend $=0.02)$, when comparing the highest quartile of intake to the lowest. Significant interactions were detected between body mass index and both saturated and monounsaturated $\mathrm{FAs}$, with a markedly reduced risk associated with intake of stearate $(\mathrm{OR}=0.36 ; 95 \% \mathrm{Cl} 0.18-0.70$; $P$-trend $=0.00 \mathrm{I})$, oleate $(\mathrm{OR}=0.36 ; 95 \% \mathrm{Cl} 0.19-0.72 ;$-trend $=0.002)$, saturated $\mathrm{FAs}(\mathrm{OR}=0.35 ; 95 \% \mathrm{Cl} 0.18-0.67$; $P$-trend $=0.002)$, and monounsaturated FAs $(\mathrm{OR}=0.32 ; 95 \% \mathrm{Cl} 0.16-0.63$; P-trend $<0.000 \mathrm{I})$ among subjects who are obese. The results suggest that substituting polyunsaturated FAs with saturated or monounsaturated FAs may reduce pancreatic cancer risk, independently of total energy intake, particularly among obese subjects.
\end{abstract}

British Journal of Cancer (2005) 92, 97I-977. doi: I0.1038/sj.bjc.6602380 www.bjcancer.com

Published online I February 2005

(C) 2005 Cancer Research UK

Keywords: pancreatic cancer; fatty acid; stearate; oleate; fat; food frequency questionnaire; diet; cancer prevention

Pancreatic cancer represents the fourth leading cause of cancerrelated deaths in Canada (CCS, 2004), and is among the most rapidly fatal cancer worldwide (WHO/IARC, 2003). The prognosis of subjects with pancreatic cancer is extremely poor since diagnosis is usually late due to lack of symptoms. The median survival time, regardless of therapy, is about $2-3$ months after diagnosis, with a 5 -year survival of about $4 \%$ (Ries et al, 2002).

\footnotetext{
* Correspondence: Dr P Ghadirian, Epidemiology Research Unit, Research Centre, (CHUM)-Hôtel-Dieu, Pavillon Masson, 3850 St Urbain St, Montreal, QC, Canada H2W IT7;

E-mail: parviz.ghadirian@umontreal.ca

${ }^{4}$ The Canadian Cancer Registries Epidemiology Research Group comprises a Principal Investigator from each of the Provincial Cancer Registries: B Paulse, Newfoundland Cancer Foundation; R Dewar, Nova Scotia Cancer Registry; D Dryer, Prince Edward Island Cancer Registry; N Kreiger, Cancer Care Ontario; E Kliewer, Cancer Care Manitoba; D Robson, Saskatchewan Cancer Foundation; S Fincham, Division of Epidemiology, Prevention and Screening, Alberta Cancer Board; and N Le, British Columbia Cancer Agency

Received 13 September 2004; revised 8 December 2004; accepted 10 December 2004; published online I February 2005
}

Experimental studies of pancreatic cancer indicate that while dietary fat per se does not cause pancreatic cancer (Roebuck, 1992), individual polyunsaturated fatty acids (FAs), but not monounsaturated or saturated FAs, have an inhibitory effect on the growth of human pancreatic cancer cell lines (Falconer et al, 1994), suggesting that an association between dietary fats and pancreatic cancer may depend on the level of specific FA intake.

An elevated risk of pancreatic cancer in relation to high dietary total fat (Durbec et al, 1983; Ghadirian et al, 1991; Howe and Burch, 1996) and saturated fat intake (Ghadirian et al, 1991; Howe and Burch, 1996; Stolzenberg-Solomon et al, 2002) has been reported. Although no association with total or saturated fat intake has been found (Farrow and Davis, 1990; Kalapothaki et al, 1993), a significant decrease in risk with higher saturated (Bueno de Mesquita et al, 1990, 1991; Zatonski et al, 1991; Ji et al, 1995; Silverman et al, 1998), monounsaturated (Bueno de Mesquita et al, 1990; Zatonski et al, 1991), and polyunsaturated (Zatonski et al, 1991) fat intake has been reported. A recent cohort study found no significant association in relation to specific FAs (Michaud et al, 2003), but included less than 180 cases over 18 years of follow-up. The present case-control study, based on data from the Canadian National Enhanced Cancer Surveillance System (NECSS), 
examined whether the intake of specific FAs was associated with pancreatic cancer risk.

\section{METHODS}

\section{Study population}

The NECSS is a multi-site, population-based, case-control study involving 21022 participants with one of 19 types of cancer identified through cancer registries in eight of the 10 Canadian provinces, namely Alberta, British Columbia, Manitoba, Newfoundland, Nova Scotia, Ontario, Prince Edward Island, and Saskatchewan. The present investigation includes only pancreatic cancer cases, and is restricted to data obtained from direct (rather than proxy) interviews. The study population has been described in detail elsewhere (Villeneuve et al, 2000). Briefly, between April 1, 1994 and December 31, 1997, the participating provincial registries identified pancreatic cancer cases as early as possible in the registration process, to minimise the loss of subjects from this rapidly fatal disease. All pancreatic cancer cases included in the NECSS were confirmed histologically, and defined according to the WHO's International Classification of Diseases, rubric 157 (WHO, 1985). Like most other studies of pancreatic cancer, the proportion of cases subject to direct interview was low. Among men diagnosed with pancreatic cancer, $30 \%$ had died before an interview could be conducted, and consent was not granted by physicians for an additional $15 \%$. Among women, $28 \%$ had died before they could be contacted, and the attending physician refused consent to approach patients for an additional $16 \%$. The vast majority of cases were ascertained within 1-3 months of diagnosis; physician consent to contact patients was generally obtained within 1 month, and approximately $70 \%$ of questionnaires were returned within 2 months of mailing. Response rates of eligible cases were $55 \%$ for men and $56 \%$ for women.

The NECSS used frequency matching in selecting the control population to achieve age and gender distributions similar to those of all cancer cases combined. Based on the projected number of incident cancer cases by province, the questionnaires were mailed to 8117 subjects during the 1996 calendar year using the same protocol as for cases. Questionnaires were not returned for 573 controls $(7.4 \%)$ because of incorrect or changed addresses. Strategies for control selection varied by province, depending on data accessibility. In Prince Edward Island, Nova Scotia, Manitoba, Saskatchewan, and British Columbia, provincial health insurance plans were tapped to obtain a random sample of the provincial population stratified by age and gender. In each of these provinces, more than $95 \%$ of residents are covered by public health care plans. Active military personnel and their families as well as indigenous peoples were excluded because they were covered by other plans. In Ontario, Ministry of Finance data were used to derive a stratified random sample, while Newfoundland and Alberta adopted a random digit-dialling method to enrol a population-based sample of controls. A total of 5039 controls were selected to serve as a common control group for all types of cancer. Response rates of 65 and $71 \%$ were achieved from the respective male and female control populations.

Questionnaires, with telephone follow-up for clarification when necessary, were mailed to subjects to obtain information on residential and occupational history and other risk factors for cancer. The NECSS questionnaire included questions on smoking history, height, weight, physical activity, and educational attainment.

\section{Dietary assessment}

Food consumption data were obtained via a semi-quantitative food frequency questionnaire (FFQ) developed after two instruments that have been widely validated previously: the short Block questionnaire (Block et al, 1990) and the Willett questionnaire (Willett, 1998). Subtle changes were made to the questionnaire items to take into account differences in American and Canadian dietary practices. The FFQ includes questions on 69 different food and beverage items, including the frequency of consumption and the amounts consumed. Participants were asked how often they had consumed these foods per week in the period 2 years prior to interview. Daily FA intakes were determined by summing the FA content of each food and beverage item in the FFQ, based on reference values given in the 1997 Canadian Nutrient File (CNF).

\section{Statistical analysis}

Data were collected on 475 cases (264 men, 211 women) and 4802 controls (2377 men, 2425 women). We excluded subjects with daily energy intake $<500 \mathrm{kcal}$ ( 10 cases and 54 controls) or $>5000 \mathrm{kcal}$ (three cases and 27 controls) because such intakes are unrealistic and hence of questionable validity. Finally, a total of 462 cases (258 men, 204 women) and 4721 frequency-matched controls (2331 men, 2390 women) were eligible for analysis.

Food intake among the cases and controls was converted to specific FA intake based on the CNF. To determine the associations between dietary FA intakes and pancreatic cancer risk, the study subjects were divided into four categories according to quartiles of calorie-adjusted FA intake in the control population. Odds ratios (ORs) and associated 95\% confidence intervals (CIs) were calculated based on unconditional logistic regression. Risk estimates were adjusted for matching variables (age group and province), lifetime cigarette consumption $(0,>0-15$, and $>15$ pack-years), body mass index (BMI) $(<25,25-29.9$, and $\geqslant 30 \mathrm{~kg} \mathrm{~m}^{-2}$ ), educational attainment (years), total fat intake $\left(\mathrm{g} \mathrm{day}^{-1}\right)$, and total energy intake. To evaluate effect modification by BMI, age, educational attainment, smoking, and physical activity, the $P$-value for a multiplicative interaction term added to the fully adjusted model was examined - and when it was statistically significant, the analysis was stratified on that variable. Tests for linear trend in the variables included in logistic regression models were performed with scores derived from the median values of categorised variables, and entered into the model as successive integers. All tests of statistical significance were twosided. Data analysis was performed using SPSS for WINDOWS (release 10.02, 1999; SPSS Inc., Chicago, IL, USA).

\section{RESULTS}

Selected characteristics of the study population are presented in Table 1. The age distributions of cases and controls were somewhat similar although there was a slight excess of younger control subjects, and cases were more likely to consume high amounts of tobacco. Two years prior to the diagnosis of cancer, a tendency towards heightened pancreatic cancer risk with increased BMI was noted, while there were no appreciable differences between cases and controls with respect to physical activity. Cases were more likely to have higher fat intake and greater total energy intake than controls.

The major sources of butyric acid were milk and icecream. Lauric acid, stearic acid, and saturated FAs were derived primarily from butter and cheese. Palmitic acid was mainly supplied by bacon, while oleic acid, linoleic acid, and alpha-linolenic acid were derived from nuts and butter, nuts and chips, and mayonnaise, respectively. Arachidonic acid was from fish and chicken, eicosapentaenoic acid and docosahexaenoic acid were exclusively from fish, while trans FAs were from margarine and mayonnaise.

The relationships between lifestyle variables and selected FAs are summarised in Table 2. Age was positively associated with both palmitate and saturated FAs, and inversely associated with oleate 
and monounsaturated FAs, but not with stearate. BMI was inversely related to palmitate, saturated and monounsaturated FAs, but not to stearate or oleate. Smoking was positively linked with palmitate, stearate, oleate, saturated and monounsaturated FAs. Educational attainment was positively associated with palmitate and inversely associated with stearate, but not with oleate, saturated or monounsaturated FAs. Total fat intake was positively related to stearate, oleate, saturated and monounsaturated FAs, but inversely related to palmitate.

Table 3 presents the ORs and corresponding 95\% CIs for pancreatic cancer according to categories of dietary FA intakes. After adjustment for age, province, educational attainment, smoking, BMI, total fat, and total energy intake, a significant inverse association was observed in women between pancreatic

Table I Selected characteristics of the study population $(n=5 \mid 83)$, National Enhanced Cancer Surveillance System, Canada, 1994-1997

\begin{tabular}{|c|c|c|c|c|}
\hline \multirow[b]{2}{*}{ Characteristic } & \multicolumn{2}{|c|}{ Cases $(n=462)$} & \multicolumn{2}{|c|}{ Controls $(n=472 I)$} \\
\hline & $n$ & $\%$ & $n$ & $\%$ \\
\hline \multicolumn{5}{|l|}{ Age (years) } \\
\hline $30-34$ & 5 & 1 & 186 & 4 \\
\hline $35-39$ & 8 & 2 & 264 & 6 \\
\hline $40-44$ & 18 & 4 & 333 & 7 \\
\hline $45-49$ & 28 & 6 & 448 & 9 \\
\hline $50-54$ & 48 & 10 & 426 & 9 \\
\hline $55-59$ & 58 & 13 & 486 & | | \\
\hline $60-64$ & 85 & 18 & 701 & 15 \\
\hline $65-69$ & 115 & 25 & 914 & 19 \\
\hline $70-74$ & 97 & 21 & 963 & 20 \\
\hline \multicolumn{5}{|c|}{ Cigarette consumption (pack-years) } \\
\hline 0 & 144 & 31 & 1767 & 38 \\
\hline$>0-15$ & 93 & 20 & 1384 & 29 \\
\hline$>15$ & 219 & 48 & 1517 & 32 \\
\hline Missing & 6 & 1 & 53 & I \\
\hline \multicolumn{5}{|c|}{ BMI 2 years prior to diagnosis $\left(\mathrm{kg} \mathrm{m}^{-2}\right)$} \\
\hline$<25$ & 188 & 41 & 2235 & 47 \\
\hline $25-29.9$ & 173 & 37 & 1816 & 39 \\
\hline$\geqslant 30$ & 101 & 22 & 670 & 14 \\
\hline \multicolumn{5}{|c|}{ Physical activity (total number of hours week ${ }^{-1}$ ) } \\
\hline$<21$ & 135 & 29 & 1168 & 25 \\
\hline $21-23$ & 228 & 49 & 2550 & 54 \\
\hline$\geqslant 23$ & 99 & 22 & 1003 & 21 \\
\hline $\begin{array}{l}\text { Daily fat intake } \\
\text { (mean } \pm \text { s.d. in g) }\end{array}$ & $61 \pm 35$ & $55 \pm 28$ & & \\
\hline $\begin{array}{l}\text { Daily energy } \\
\text { intake }^{a b} \\
\text { (mean } \pm \text { s.d. in kcal) }\end{array}$ & $1862 \pm 757$ & $1723 \pm 642$ & & \\
\hline
\end{tabular}

a,bThese differences are significant, $P<0.001$ cancer risk and palmitate $(\mathrm{OR}=0.73 ; 95 \%$ CI $0.56-0.96 ; P$ trend $=0.02)$, stearate $(\mathrm{OR}=0.70 ; 95 \%$ CI $0.51-0.94 ; P$-tren$\mathrm{d}=0.04)$, oleate $(\mathrm{OR}=0.75 ; 95 \%$ CI $0.55-1.02 ; P$-trend $=0.04)$, total saturated FAs $(\mathrm{OR}=0.67 ; 95 \% \mathrm{CI} 0.50-0.91 ; P$-trend $=0.01)$, and monounsaturated FAs $(\mathrm{OR}=0.72 ; 95 \%$ CI $0.53-0.98 ; P$ trend $=0.02$ ), when comparing the highest quartile of intake to the lowest.

There was a significant interaction between BMI and stearic acid $(P=0.04)$ as well as oleic acid $(P=0.04)$, and both total saturated and monounsaturated FAs $(P=0.05)$. The risk of pancreatic cancer in relation to intake of stearate, oleate, total saturated and monounsaturated FAs is presented in Table 4 by categories of BMI. Among obese subjects, strong and significant inverse associations were apparent between stearic acid $(\mathrm{OR}=0.36 ; 95 \%$ CI $\quad 0.18-0.70 ; \quad P$-trend $=0.001)$, oleic acid $(\mathrm{OR}=0.36 ; 95 \%$ $\mathrm{CI}=0.19-0.72 ; P$-trend $=0.002)$, saturated $\mathrm{FAs}(\mathrm{OR}=0.35 ; 95 \%$ CI $0.18-0.67 ; \quad P$-trend $=0.002)$, and monounsaturated FAs $(\mathrm{OR}=0.32 ; 95 \%$ CI $0.16-0.61 ; P$-trend $=0.001)$ and pancreatic cancer risk, when comparing the highest to the lowest quartile of intakes. There was no evidence of effect modification by age, educational attainment, smoking, and physical activity ( $P$ for interaction $>0.05$ in all cases, data not shown).

\section{DISCUSSION}

In this population-based case-control study of specific FAs and pancreatic cancer, we found that palmitic acid, stearic acid, and total saturated FA intakes were associated with a significantly decreased risk. Our findings are in agreement with those of five previous case-control studies that reported statistically significant or borderline decreased risks of pancreatic cancer with higher saturated fat intake, with a relative risk of 0.3 (95\% CI $0.1-0.8), 0.3$ (95\% CI $0.1-1.0), 0.2$ (95\% CI $0.1-0.2)$, and 0.9 ( $P$-trend $=0.028$; for men) for intakes in the highest as compared to the lowest quartiles (Baghurst et al, 1991; Bueno de Mesquita et al, 1991; Zatonski et al, 1991; Silverman et al, 1998), respectively. A large collaborative population-based case-control of pancreatic cancer comprising 802 cases from five countries in the Surveillance of Environmental Aspects Related to Cancers in Humans (SEARCH) Study found a nonsignificant reduced risk, with an overall OR of 0.8 (95\% CI $0.6-1.2)$ for the highest quartile of saturated fat intake (Howe et al, 1992), with significant inverse associations reported in two study centres (Howe and Burch, 1996).

In contrast, three case-control and two cohort studies reported no significant association (Kalapothaki et al, 1993; Howe and Burch, 1996; Michaud et al, 2003) or an increased risk associated with higher saturated fat intake (Ghadirian et al, 1991; Stolzenberg-Solomon et al, 2002). The latter investigations reporting an increased risk utilised specific populations such as French Canadians or male smokers who may have particular food habits and dietary patterns. Levels of saturated FA intakes were substantially higher in the case-control by Ghadirian et al and in the cohort study by Stolzenberg-Solomon et al. The mean

Table 2 Relationships between selected lifestyle factors and calorie-adjusted fatty acid intakes

\begin{tabular}{|c|c|c|c|c|c|}
\hline \multirow[t]{2}{*}{ Fatty acid } & Age & BMI & Smoking & Educational attainment & Total fat intake \\
\hline & \multicolumn{4}{|c|}{ Beta (s.e.) ${ }^{a}$} & \\
\hline $\begin{array}{l}\text { Palmitate } \\
\text { Stearate } \\
\text { Oleate } \\
\text { Saturated FAs } \\
\text { Monounsaturated FAs }\end{array}$ & $\begin{array}{r}0.25(0.1)^{*} \\
-0.11(0.1)^{\dagger} \\
-0.32(0.1)^{\dagger} \\
0.15(0.1)^{*} \\
-0.32(0.1)^{\dagger}\end{array}$ & $\begin{array}{r}-0.96(0.3)^{\dagger} \\
-0.14(0.2) \\
0.25(0.1) \\
-0.53(0.2)^{*} \\
0.21(0.1)\end{array}$ & $\begin{array}{l}0.26(0.1)^{\dagger} \\
0.28(0.0)^{\dagger} \\
0.13(0.0)^{\dagger} \\
0.12(0.0)^{*} \\
0.12(0.0)^{\dagger}\end{array}$ & $\begin{array}{r}0.12(0.4)^{*} \\
-0.49(0.2)^{*} \\
0.04(0.2) \\
-0.11(0.2) \\
0.04(0.2)\end{array}$ & $\begin{array}{l}-4.27(1.4)^{*} \\
85.10(0.7)^{\dagger} \\
89.00(0.6)^{\dagger} \\
82.00(0.8)^{\dagger} \\
90.70(0.6)^{\dagger}\end{array}$ \\
\hline
\end{tabular}

${ }^{a} \mathrm{FA}=$ fatty acid. Parameter estimates $(\beta$ coefficient and standard error in \%) from regression with palmitate, stearate, oleate, saturated and monounsaturated FAs as dependent variables and age, $\mathrm{BMI}$, smoking, educational attainment and total fat intake as independent variables. ${ }^{*} P<0.05 .{ }^{\dagger} P \leqslant 0.001$. 
Table $3 \mathrm{ORs}^{\mathrm{a}}$ and $95 \% \mathrm{Cls}$ for pancreatic cancer associated with dietary fatty acids

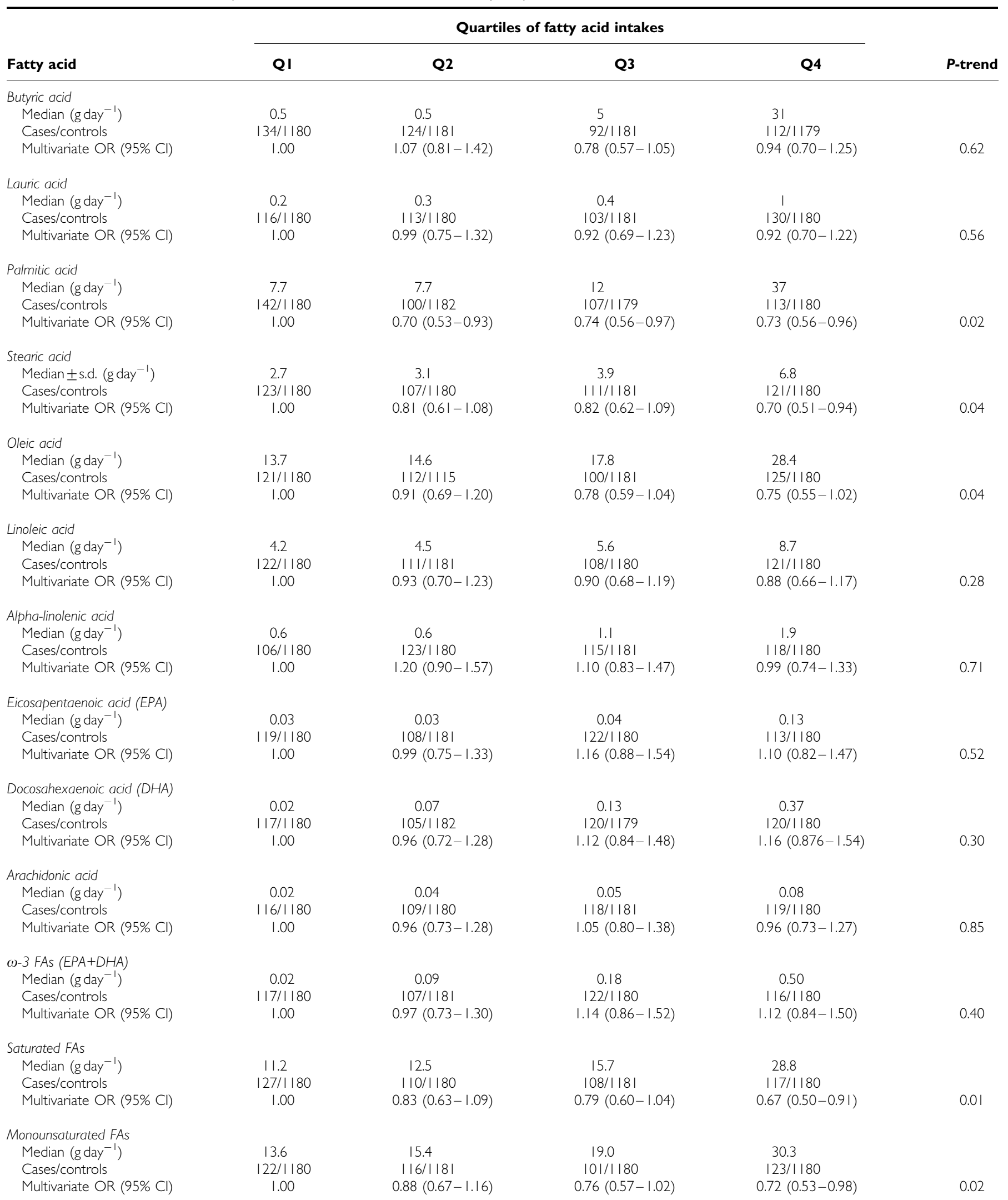


Quartiles of fatty acid intakes

\begin{tabular}{|c|c|c|c|c|c|}
\hline \multirow[b]{2}{*}{ Fatty acid } & & & & & \multirow[b]{2}{*}{ P-trend } \\
\hline & Q I & Q2 & Q3 & Q4 & \\
\hline \multicolumn{6}{|l|}{ Polyunsaturated FAs } \\
\hline Median $\left(\right.$ g day $\left.^{-1}\right)$ & 5.2 & 5.6 & 7.1 & 10.9 & \\
\hline Cases/controls & $123 / 1180$ & $105 / 1|8|$ & $117 / 1180$ & $117 / 1180$ & \\
\hline Multivariate OR (95\% Cl) & 1.00 & $0.90(0.68-1.19)$ & $0.97(0.74-1.28)$ & $0.83(0.62-1.11)$ & 0.22 \\
\hline \multicolumn{6}{|l|}{ trans-FAs } \\
\hline Median $\left(\right.$ g day $\left.^{-1}\right)$ & 0.3 & 0.6 & I. & 2.8 & \\
\hline Cases/controls & $97 / 1180$ & || $4 /|| 8 \mid$ & $123 / 1180$ & $128 / 1180$ & \\
\hline Multivariate OR $(95 \% \mathrm{Cl})$ & 1.00 & $1.21(0.90-1.62)$ & $1.21(0.90-1.62)$ & $1.08(0.80-1.44)$ & 0.50 \\
\hline
\end{tabular}

Table $4 \mathrm{ORs}^{\mathrm{a}}$ and $95 \% \mathrm{Cls}$ for pancreatic cancer associated with saturated and monounsaturated fatty acids and body mass index

\begin{tabular}{|c|c|c|c|c|c|c|}
\hline \multirow[b]{2}{*}{ Body mass index } & \multirow[b]{2}{*}{ Fatty acids } & \multicolumn{4}{|c|}{ Quartiles of fatty acid intakes } & \multirow[b]{2}{*}{$P$-trend } \\
\hline & & QI & Q2 & Q3 & Q4 & \\
\hline$\geqslant 30$ & $\begin{array}{l}\text { Stearic acid } \\
\text { Oleic acid } \\
\text { Saturated FAs } \\
\text { Monounsaturated FAs }\end{array}$ & 1.00 & $\begin{array}{l}0.62(0.34-1.14) \\
0.67(0.36-1.23) \\
0.40(0.21-0.76) \\
0.72(0.39-1.31)\end{array}$ & $\begin{array}{l}0.38(0.20-0.74) \\
0.36(0.18-0.72) \\
0.42(0.23-0.79) \\
0.37(0.19-0.73)\end{array}$ & $\begin{array}{l}0.36(0.18-0.70) \\
0.36(0.19-0.72) \\
0.35(0.18-0.67) \\
0.32(0.16-0.61)\end{array}$ & $\begin{array}{l}0.001 \\
0.002 \\
0.002 \\
0.001\end{array}$ \\
\hline
\end{tabular}

${ }^{\mathrm{a}} \mathrm{FA}=$ fatty acid. Odds ratios and 95\% confidence intervals from the logistic regression model adjusted for age, province, educational attainment, smoking, total fat and energy intake.

saturated fat intake among French-Canadians was $55.2 \pm$ $40.6 \mathrm{~g} \mathrm{day}^{-1}$ for cases and $42.2 \pm 27.0 \mathrm{~g} \mathrm{day}^{-1}$ for controls compared with $18.2 \pm 11.3 \mathrm{~g} \mathrm{day}^{-1}$ for cases and $20.0 \pm 13.7$ for controls in our study. The median saturated fat intake among male smokers was $61.8 \mathrm{~g} \mathrm{day}^{-1}$ for cases and $58.5 \mathrm{~g} \mathrm{day}^{-1}$ for nonaffected, compared with $16.2 \mathrm{~g} \mathrm{day}^{-1}$ for cases and $15.3 \mathrm{~g} \mathrm{day}^{-1}$ for controls in the present investigation; this observation may partly explain the lack of consistency among these studies.

Palmitate and stearate are the most common long-chain saturated FAs. The dietary intake of these two specific was related to $27-30 \%$ risk reduction, and a $33 \%$ decrease in pancreatic cancer risk with total saturated FA intake. The mechanisms by which these relationships may be explained are areas of current active research. A high fat intake affects pancreatic cancer risk by stimulating cholecystokinin (CCK) release, which, in rodents, increases susceptibility to carcinogens and causes acinar cell hyperplasia, followed by the development of pancreatic carcinomas (Longnecker, 1993; Chu et al, 1997). In humans, it has been suggested that duodenal CCK release might differ significantly according to the degree of fat saturation, with unsaturated FAs being stronger stimulants of CCK release than saturated FAs (Beardshall et al, 1989). In response to meals containing different fats, CCK release is enhanced by one-, two-, and six-fold for saturated, monounsaturated, and polyunsaturated FAs, respectively. If the hypothesis that the promoting effect of dietary fat on pancreatic carcinogenesis is mediated via CCK is correct, this could partly explain the reduced pancreatic cancer risk associated with both specific and total saturated FAs.

Oleic acid is a major monounsaturated FA. We found a $25 \%$ (statistically significant) risk reduction related to oleate intake, with monounsaturated FA intake associated with a $28 \%$ decrease in pancreatic cancer risk. One case-control study (Zatonski et al, 1991) in Poland found a strong decrease in pancreatic cancer risk $(\mathrm{OR}=0.10 ; P$-trend $=0.02)$ with higher monounsaturated fat intake. Another case-control study (Bueno de Mesquita et al, $1990)$ in the Netherlands reported a $60 \%$ nonsignificant decrease in risk among men, but not among women. Other studies have detected no statistically significant association with monounsaturated FAs (Howe et al, 1990; Michaud et al, 2002).

Few risk factors for pancreatic cancer have been consistently identified. In the present study age, BMI, smoking, educational attainment, and total fat intake were clearly related to palmitate, stearate, oleate, saturated and monounsaturated FAs. We found that adjustments increased the magnitude of the association between these FAs and pancreatic cancer risk. Therefore, it is likely that the factors we included in the model are simultaneously confounding and may be responsible for this effect.

Pancreatic cancer risk reduction in relation to dietary intake of stearic acid, oleic acid, and both total saturated and monounsaturated FAs remained evident among obese subjects. Saturated and 
monounsaturated FA intakes were associated with strong and significantly decreased pancreatic cancer risk in obese subjects $(\mathrm{BMI} \geqslant 30)$, with 65 and $68 \%$ risk reductions, respectively. A cohort study of pancreatic cancer indicated that dietary glycaemic load and the glycaemic index are associated with increased risk of pancreatic cancer among women who were overweight, and among obese women with low physical activity (Michaud et al, 2002). Obesity is a physiological state that is accompanied by abnormal glucose metabolism and greater insulin resistance. Since the pharmacokinetic properties of both saturated and monounsaturated FAs are not known to depend on BMI, it is likely that obese subjects may be particularly susceptible to the type of FA they consume, likely because of some degree of repression of CCK release. However, the significance of such susceptibility is speculative and remains to be established.

The major strengths of our study included the large number of pancreatic cancer cases, histological diagnosis, and general population sampling of controls. The large sample size permitted subgroup analyses. Histological confirmation of diagnosis reduced the possibility of disease misclassification, while a populationbased approach facilitates extrapolation of results to the general population.

Our study is also subject to certain limitations. Since the assessment of dietary exposure was retrospective, recall bias cannot be completely excluded. A prospective cohort approach has several advantages when studying associations between nutritional factors and cancer risk. However, because of the relatively low incidence of pancreatic cancer, the largest cohort to date examining diet and pancreatic cancer risk confirmed only 178 pancreatic cancer cases in 18 years of follow-up (Michaud et al, 2003).

We could not adjust OR estimates for the potentially confounding effects of diabetes mellitus and family history of pancreatic cancer, since this information was not collected at baseline. Nevertheless, we expected that diabetes did not confound the association between specific FA intakes and pancreatic cancer risk because of the likelihood that diet represents the initial risk factor for both chronic diseases, rather than lying on the causal pathway. In addition, it has been suggested that diabetes might be one of the early manifestations of pancreatic cancer, and the significance of diabetes is much weaker if cases of recent onset are excluded (WHO/AIRC, 2003). As well, it is unlikely that the confounding effect of family aggregation of pancreatic cancer may explain the significantly inverse associations we found because genetic/familial predisposition is rare (Ghadirian et al, 2003). Another limitation is the consequence of early and high case fatality associated with the disease. As in other epidemiological studies of pancreatic cancer, cases died before the questionnaire could be administered were not included in the analysis. However, since there was no discrimination in the selection of study subjects based on their demographic characteristics and lifestyle factors, such as age, smoking or educational attainment, survivors are still representative of the study population. Consequently, bias of this kind, if any, is unlikely to be substantial.

In conclusion, our current analyses suggest that, independently of total energy intake, substituting polyunsaturated FAs with saturated or monounsaturated FAs may reduce pancreatic cancer risk, particularly in subjects who are obese. Further epidemiological studies assessing the role of specific dietary FA intakes in the aetiology of pancreatic cancer are warranted.

\section{ACKNOWLEDGEMENTS}

The present study was funded with the support of the National Cancer Institute of Canada (NCIC) through a fellowship awarded to Dr Nkondjock, and with the support of the Natural Sciences and Engineering Research Council of Canada (NSERC), the Social Sciences and Engineering Research Council of Canada (SSHRC), and the McLaughlin Foundation through a Research Chair awarded to Dr Krewski. Health Canada supported the NECSS, in collaboration with the provincial cancer registries, through its Health and the Environment initiative. The Canadian Cancer Registries Epidemiology Research Group comprises a Principal Investigator from each of the Provincial Cancer Registries: B Paulse, Newfoundland Cancer Foundation; R Dewar, Nova Scotia Cancer Registry; D Dryer, Prince Edward Island Cancer Registry; N Kreiger, Cancer Care Ontario; E Kliewer, Cancer Care Manitoba; D Robson, Saskatchewan Cancer Foundation; S Fincham, Division of Epidemiology, Prevention and Screening, Alberta Cancer Board; and $\mathrm{N}$ Le, British Columbia Cancer Agency.

\section{REFERENCES}

Baghurst PA, McMichael AJ, Slavotinek AH, Baghurst KI, Boyle P, Walker AM (1991) A case-control study of diet and cancer of the pancreas. Am J Epidemiol 134: $167-179$

Beardshall K, Frost G, Morarji Y, Domin J, Bloom SR, Calam J (1989) Saturation of fat and cholecystokinin release: implications for pancreatic carcinogenesis. Lancet 2: 1008-1010

Block G, Hartman AM, Naughton D (1990) A reduced dietary questionnaire: development and validation. Epidemiology 1: 58-64

Bueno de Mesquita HB, Maisonneuve P, Runia S, Moerman CJ (1991) Intake of foods and nutrients and cancer of the exocrine pancreas: a population-based case-control study in The Netherlands. Int J Cancer 48: $540-549$

Bueno de Mesquita HB, Moerman CJ, Runia S, Maisonneuve P (1990) Are energy and energy-providing nutrients related to exocrine carcinoma of the pancreas? Int J Cancer 46: 435-444

Canadian Cancer Society (2004) Available at: http://www.cancer.ca

Chu M, Rehfeld JF, Borch K (1997) Chronic endogenous hypercholecystokininemia promotes pancreatic carcinogenesis in the hamster. Carcinogenesis 18: $315-320$

Durbec JP, Chevillotte G, Bidart JM, Berthezene P, Sarles H (1983) Diet, alcohol, tobacco and risk of cancer of the pancreas: a case-control study. Br J Cancer 47: 463 - 470

Falconer JS, Ross JA, Fearon KC, Hawkins RA, O'Riordain MG, Carter DC (1994) Effect of eicosapentaenoic acid and other fatty acids on the

growth in vitro of human pancreatic cancer cell lines. Br J Cancer 69: $826-832$

Farrow DC, Davis S (1990) Diet and the risk of pancreatic cancer in men. Am J Epidemiol 132: 423-431

Ghadirian P, Lynch HT, Krewski D (2003) Epidemiology of pancreatic cancer: an overview. Cancer Detect Prev 27: 87-93

Ghadirian P, Simard A, Baillargeon J, Maisonneuve P, Boyle P (1991) Nutritional factors and pancreatic cancer in the francophone community in Montreal, Canada. Int J Cancer 47: 1-6

Howe GR, Burch JD (1996) Nutrition and pancreatic cancer. Cancer Causes Control 7: 69-82

Howe GR, Ghadirian P, Bueno de Mesquita HB, Zatonski WA, Baghurst PA, Miller AB, Simard A, Baillargeon J, de Waard F, Przewozniak K (1992) A collaborative case-control study of nutrient intake and pancreatic cancer within the search programme. Int J Cancer 51: 365-372

Howe GR, Jain M, Miller AB (1990) Dietary factors and risk of pancreatic cancer: results of a Canadian population-based case-control study. Int $J$ Cancer 45: 604-608

Ji BT, Chow WH, Gridley G, Mclaughlin JK, Dai Q, Wacholder S, Hatch MC, Gao YT, Fraumeni Jr JF (1995) Dietary factors and the risk of pancreatic cancer: a case-control study in Shanghai China. Cancer Epidemiol Biomarkers Prev 4: 885-893

Kalapothaki V, Tzonou A, Hsieh CC, Karakatsani A, Trichopoulou A, Toupadaki N, Trichopoulos D (1993) Nutrient intake and cancer of the 
pancreas: a case-control study in Athens, Greece. Cancer Causes Control 4: $383-389$

Longnecker DS (1993) Experimental models of exocrine pancreatic tumors. In The Pancreas, Biology, Pathobiology, and Disease, 2nd edn GO VLW, DiMagno EP, Gardner JD, Liebenthal E, Reber HA, Scheele GA (eds) pp 551 - 564. New York: Raven Press

Michaud DS, Giovannucci E, Willett WC, Colditz GA, Fuchs CS (2003) Dietary meat, dairy products, fat, and cholesterol and pancreatic cancer risk in a prospective study. Am J Epidemiol 157: $1115-1125$

Michaud DS, Liu S, Giovannucci E, Willett WC, Colditz GA, Fuchs CS (2002) Dietary sugar, glycemic load, and pancreatic cancer risk in a prospective study. J Natl Cancer Inst 94: 1293 - 1300

Ries LG, Eisner MP, Kosary CL, Hankey BF, Miller BA, Clegg L, Mariotto A, Feuer EJ, Edwards BK (2002) SEER Cancer Statistics Review, 1975-2001. Bethesda, MD: National Cancer Institute http://seer.cancer.gov/csr/ 1975_2001/

Roebuck BD (1992) Dietary fat and the development of pancreatic cancer. Lipids 27: $804-806$

Silverman DT, Swanson CA, Gridley G, Wacholder S, Greenberg RS, Brown LM, Hayes RB, Swanson GM, Schoenberg JB, Pottern LM, Schwartz AG,
Fraumeni Jr JF, Hoover RN (1998) Dietary and nutritional factors and pancreatic cancer: a case-control study based on direct interviews. J Natl Cancer Inst 90: 1710-1719

Stolzenberg-Solomon RZ, Pietinen P, Taylor PR, Virtamo J, Albanes D (2002) Prospective study of diet and pancreatic cancer in male smokers. Am J Epidemiol 155: 783 - 792

Villeneuve PJ, Johnson KC, Hanley AJ, Mao Y (2000) Alcohol, tobacco and coffee consumption and the risk of pancreatic cancer: results from the Canadian Enhanced Surveillance System case-control project. Canadian Cancer Registries Epidemiology Research Group. Eur J Cancer Prev 9: $49-58$

Willett W (ed) (1998) Nutritional Epidemiology, 2nd edn pp 95-97. New York: Oxford University Press

World Health Organization (1985) International Classification of Diseases, 9th revision Geneva: WHO

World Health Organization, International Agency for Research on Cancer (2003) In World Cancer Report Steward BW, Kleihues P (eds) pp 248252. Lyon: IARC Press

Zatonski W, Przewozniak K, Howe GR, Maisonneuve P, Walker AM, Boyle P (1991) Nutritional factors and pancreatic cancer: a case-control study from south-west Poland. Int J Cancer 48: 390-394 